ISSN 0103-9954

\title{
INFLUÊNCIA DO BRANQUEAMENTO COM OZÔNIO E PERÓXIDO DE HIDROGÊNIO NO RENDIMENTO E QUALIDADE DE FIBRAS SECUNDÁRIAS
}

\author{
INFLUENCE OF BLEACHING WITH OZONE AND PEROXIDO OF HYDROGEN IN THE YIELD AND \\ QUALITY OF SECONDARY FIBERS
}

Gustavo Ventorim $^{1}$ Jorge L. Colodette ${ }^{2}$

\section{RESUMO}

Nesse estudo, foram avaliadas seqüências "Total Chlorine Free" (TCF) para o branqueamento de fibras secundárias provenientes de três fontes diferentes. As polpas foram branqueadas a um nível mínimo de alvura de $78 \%$ ISO, sendo que a quantidade necessária de reagentes e as suas principais propriedades foram avaliadas. A utilização do ozônio mostrou-se eficiente no branqueamento TCF, pois permitiu alcançar a alvura objetivo nos três tipos de polpas, por meio das seqüências (ZQ)P e (ZQ)(PO). As letras apresentadas nas seqüências de branqueamento possuem os seguintes significados: os estágios de ozônio, $Z$, seguido de uma quelação, $\mathrm{Q}$, e um simples estágio de peróxido, $\mathrm{P}$, ou um estágio de peróxido pressurizado com oxigênio (PO). E também reduziu significativamente a coordenada de cor $b^{*}$ e ligeiramente a fluorescência das polpas. Os resultados de rendimento para os processos avaliados nesse estudo foram afetados negativamente por estágios alcalinos, como oxigênio, $\mathrm{O}, \mathrm{P}$ e (PO), em altas temperaturas e também pela origem das polpas de fibras secundárias.

Palavras-chave: fibras secundárias; processos de branqueamento (TCF).

\section{ABSTRACT}

In this study, Total Chlorine Free (TCF) bleaching processes were evaluated for bleaching a secondary fiber of different origens. The samples were bleached to a target brightness of $78 \%$ ISO. The results were interpreted on the basis of chemical cost to reach the target brightness, bleaching yield and bleached pulp quality as measured by viscosity, fluorescence and $b^{*}$ color coordinate. The ozone stage was responsible for improve TCF bleaching performance. The pulp bleached by sequences contained a ozone stage followed by chelation, without interstage washing (ZQ), and a final hydrogen peroxide stage unpressurized $(\mathrm{P})$ or pressurized with oxygen (PO), designed as (ZQ)(PO) showed good results. These sequences decreased pulp $\mathrm{b}^{*}$ coordinate significantly and fluorescence slightly. For all three bleaching processes, it was determined that process yield is negatively affected by hot alkaline stages such as oxygen, $\mathrm{O}$, peroxide, $\mathrm{P}$, and peroxide pressurized with oxygen, (PO) and also for the origin of the pulps of secondary fibers.

Key words: secondary fibers; bleaching process (TCF).

\section{INTRODUÇÃO}

Sob um ponto de vista ambientalista, o uso de fibras secundárias reduz o consumo de madeira. Isso, é uma das característica mais desejáveis no uso destas fibras, já que não resulta em abate de florestas D'Almeida e Cahem (1991). Por outro lado, a reciclagem de fibras contribui para um menor acúmulo de lixo nos grandes centros urbanos, e na redução de poluição hídrica e atmosférica, em relação a processos químicos de produção de fibras virgens. Por outro lado, o processo de reciclagem requer menos energia que processos mecânicos de polpação.

$\mathrm{O}$ crescimento da área urbana aliada à necessidade de preservação florestal tem reduzido as áreas florestáveis, aumentando os custos destinados à compra de terra, especialmente nos países europeus. Esse fato, resulta num incremento de preço da madeira utilizada como matéria-prima na produção de fibras virgens.

Usualmente, as fibras secundárias são branqueadas a baixas alvuras para atender a usos menos nobres do papel. O branqueamento, na sua maior parte, é efetuado com reagentes à base de cloro. São muito

1. Químico, Doutorando em Engenharia Florestal, Universidade Federal de Viçosa, CEP 36571-000, Viçosa (MG). ventorim@vicosa.ufv.br.

2. Engenheiro Florestal, PhD., Professor Titular do Departamento de Engenharia Florestal, Universidade Federal de Viçosa, CEP: 36570-000, Viçosa (MG). colodett@mail.ufv.br.

Recebido para publicação em 20/12/2002 e aceito em 9/03/2005. 
comuns os processos em uma única etapa com hipoclorito $(H)$ ou em seqüências tais como $H H$, cloração $(C)$ e hipocloração e cloração, extração (E) e hipocloração $\mathrm{CEH}$, sendo a última mais aplicável para fibras secundárias que apresentam maiores teores de lignina Stus (1996); Naddeo et al. (1992); Singh (1987). Processos de branqueamento que não envolvem o uso do cloro têm também sido utilizados, incluindo processos somente com peróxido de hidrogênio $(\mathrm{P})$ em simples e duplo estágio (PP) ou peróxido combinado com agentes redutores, tais como hidrosulfito de sódio (Y) e ácido formamidino sulfínico (FAS), em seqüências tais como PY ou PFAS Patt et al. (1996). Porém, exigências de mercado aliadas à legislações ambientais mais restritivas têm inviabilizado o branqueamento convencional, exigindo tecnologias menos agressivas ao meio ambiente.

As exigências de qualidade das fibras secundárias têm crescido acentuadamente. Tais fibras que, no passado, eram usadas para fins menos nobres, estão alcançando nichos de mercado mais exigentes, especialmente quanto aos seus níveis de alvura, que são, atualmente, ocupados por fibras virgens branqueadas vindas de madeiras de folhosas.

Em razão da grande heterogeneidade desse material, o branqueamento de fibras secundárias a elevados níveis de alvura e a custos competitivos é complexo. Outro fato importante é que o uso dos eficientes compostos à base de cloro não é mais bem aceito para branquear este tipo de fibra, sob o ponto de vista ambiental.

O branqueamento é a etapa de maior complexidade na manufatura de papéis de alta qualidade, com base em fibras secundárias. A composição das fibras secundárias é determinante, sendo que as do tipo kraft não-branqueadas e as oriundas de processos mecânicos de polpação são as que apresentam as maiores dificuldades de branqueamento. As polpas kraft não branqueadas contêm, usualmente, elevados teores de lignina modificada, pois são provenientes de caixas de papelão, e as de pasta mecânicas contêm toda a lignina não-modificada, originalmente, presente na madeira. A química de branqueamento desses dois tipos de lignina difere grandemente. Algumas fibras secundárias contêm ainda combinações de corantes e ligninas que apresentam pequena reatividade diante dos reagentes de branqueamento comercias e também possuem os pigmentos de carbono preto que não reagem. Por outro lado, resinas usadas para promover a cura de certos tipos de tintas e colas usadas na colagem do papel, podem interagir com os reagentes de branqueamento Dalton (1991); Naddeo et al. (1994a), Naddeo et al. (1994b), ); Naddeo et al. (1993a), Naddeo et al. (1993b), Naddeo e Dalton (1991).

A escolha da melhor tecnologia para o branqueamento de uma determinada amostra de fibra secundária depende, largamente, da composição de fibras do material de origem. Assim sendo, o objetivo desse estudo foi o de branquear a altos níveis de alvura, 78-82\% ISO, três diferentes polpas de fibras secundárias com processos Total Chlorine Free (TCF) de branqueamento, utilizando-se reagentes tais como, oxigênio, ozônio e peróxido de hidrogênio, avaliando o rendimento e a qualidade das polpas quanto a fluorescência, coordenada de cor $\mathrm{b}^{*}$, número kappa e viscosidade.

\section{MATERIAL E MÉTODOS}

\section{Material}

Foram utilizadas nesse estudo três amostras de fibras secundárias destintadas, sendo estas oriundas da América do Sul (AS), América do Norte (AN) e Europa (EU). As principais características iniciais das amostras encontram-se na Tabela 1.

\section{Plano Experimental}

Foram realizados processos de branqueamento TCF com as seguintes seqüências:

Amostra (AS) = Estágio de ozônio, $Z$ seguido de uma quelação, Q, (ZQ); e então, estágio de peróxido, $\mathrm{P},(\mathrm{ZQ}) \mathrm{P}$.

Amostra $(\mathrm{AN})$ = Estágio de peróxido $\mathrm{P}$; estágio de ozônio, $\mathrm{Z}$ seguido de uma quelação, $\mathrm{Q},(\mathrm{ZQ})$; e então, estágio de peróxido, $\mathrm{P},(\mathrm{ZQ}) \mathrm{P}$; e estágio de ozônio, $Z$ seguido de uma quelação, $\mathrm{Q}$ e então, estágio de peróxido pressurizado com oxigênio $(\mathrm{PO}),(\mathrm{ZQ})(\mathrm{PO})$

Amostra (EU) = estágio de ozônio, $Z$ seguido de uma quelação, $Q,(Z Q)$; e então estágio de peróxido pressurizado com oxigênio $(\mathrm{PO}),(\mathrm{ZQ})(\mathrm{PO})$ 
TABELA 1: Características físico-químicas das amostras de fibras secundárias

TABLE 1: Chemical and physical characteristics of the secondary fiber samples

\begin{tabular}{|c|c|c|c|}
\hline \multirow[t]{2}{*}{ Variáveis } & \multicolumn{3}{|c|}{ Amostras } \\
\hline & $\mathrm{AS}$ & $\mathrm{AN}$ & $\mathrm{EU}$ \\
\hline Alvura, sem UV, \% ISO & 66,0 & 55,1 & 70,4 \\
\hline Número kappa & 7,3 & 14,4 & 26,6 \\
\hline Fluorescência, \% ISO & 10,17 & 1,92 & 8,55 \\
\hline Viscosidade, mPa.s & 10,7 & 11,9 & 11,8 \\
\hline $\mathrm{L}^{*}$ & 86,6 & 85,8 & 90,0 \\
\hline$a^{*}$ & 0,251 & $-0,246$ & $-0,070$ \\
\hline$b^{*}$ & 1,19 & 11,60 & 3,90 \\
\hline Insolúveis em $\mathrm{HCl}, \%$ & 3,6 & 0,88 & 0,65 \\
\hline Sílica, \% & 2,6 & 0,36 & 0,48 \\
\hline $\mathrm{Mg}, \mathrm{ppm}$ & 210 & 178 & 23,8 \\
\hline $\mathrm{Ca}, \mathrm{ppm}$ & 8.352 & 1.309 & 1.255 \\
\hline $\mathrm{Mn}, \mathrm{ppm}$ & 8,70 & 3,28 & 0,490 \\
\hline $\mathrm{Cu}, \mathrm{ppm}$ & 26,8 & 4,31 & 1,14 \\
\hline $\mathrm{Fe}, \mathrm{ppm}$ & 435 & 79,6 & 23,0 \\
\hline
\end{tabular}

Em que: $\mathrm{AS}=$ América do Sul; $\mathrm{AN}=$ América do Norte; $\mathrm{EU}=$ Europa; $\mathrm{L}^{*}=0-$ preto e $100-$ branco; $\mathrm{a}^{*}=(+)$ vermelho e (-) verde; $b^{*}=(+)$ amarelo e (-) azul.

\section{Métodos}

As várias etapas de branqueamento foram efetuadas com amostras de tamanho variado e em diferentes reatores. O branqueamento com peróxido pressurizado (PO) foi efetuado em reator de aço-inox, com capacidade para injeção de gases e pressurização. Os estágios de peroxidação convencional e quelação (P) e (Q) foram efetuados em sacos de polietileno. O branqueamento com ozônio em média consistência foi realizado com $280 \mathrm{~g}$ de amostra de polpa em reator/misturador fabricado pela Quantum Technologies acoplado em um compressor de ozônio. As condições desses estágios se encontram na Tabela 2.

TABELA 2: Condições gerais de branqueamento.

TABLE 2: General bleaching conditions.

\begin{tabular}{|c|c|c|c|c|c|}
\hline \multirow{2}{*}{$\begin{array}{c}\text { Estágios } \\
\text { de } \\
\text { branqueamento }\end{array}$} & \multicolumn{5}{|c|}{ Condições do branqueamento } \\
\hline & $\begin{array}{c}\text { Consistência } \\
(\%)\end{array}$ & $\begin{array}{c}\text { Temperatura } \\
\left({ }^{\circ} \mathrm{C}\right)\end{array}$ & $\begin{array}{c}\text { Tempo } \\
\text { (min) }\end{array}$ & $\mathrm{pH}$ Inicial & $\begin{array}{c}\text { Pressão inicial } \\
(\mathrm{kPa})\end{array}$ \\
\hline \multicolumn{6}{|c|}{ Amostra AS } \\
\hline $\mathrm{Z}$ & $43 \pm 2$ & $\mathrm{Amb}$ & $<2$ & $2,5-2,8$ & - \\
\hline $\mathrm{Q}$ & 10 & 70 & 30 & $5,5-6,0$ & - \\
\hline $\mathrm{P}$ & 10 & 95 & 60 & 11,5 & - \\
\hline$(\mathrm{PO})$ & 10 & 95 & 60 & 11,5 & 500 \\
\hline \multicolumn{6}{|c|}{ Amostra AN } \\
\hline $\mathrm{P}$ & 10 & 70 & 120 & 11,5 & --- \\
\hline Q & 10 & 60 & 30 & $5,5-6,0$ & --- \\
\hline Z & $43 \pm 2$ & Amb. & $<2$ & $2,5-2,8$ & --- \\
\hline$(\mathrm{PO})$ & 10 & 100 & 60 & 11,5 & 500 \\
\hline \multicolumn{6}{|c|}{ Amostra EU } \\
\hline $\mathrm{Z}$ & $43 \pm 2$ & Amb. & $<2$ & $2,5-2,8$ & --- \\
\hline $\mathrm{Q}$ & 10 & 60 & 30 & $5,5-6,0$ & --- \\
\hline $\mathrm{P}$ & 10 & 60 & 120 & 11,5 & --- \\
\hline$(\mathrm{PO})$ & 10 & 95 & 120 & 11,5 & 500 \\
\hline
\end{tabular}

Em que: $\mathrm{AS}=$ América do Sul; $\mathrm{AN}=$ América do Norte; $\mathrm{EU}$ = Europa; $\mathrm{Z}$ = Ozônio; $\mathrm{P}$ = peróxido de hidrogênio; $\mathrm{Q}=$ quelação e $(\mathrm{PO})=$ peróxido pressurizado com oxigênio.

Os procedimentos analíticos e as suas respectivas normas são: 
Número kappa, TAPPI T 236 om-85, Viscosidade (CED), TAPPI T 230 om-85, Formação de folhas para medição de alvura, CPPA C.5, Alvura TAPPI T 452 om-86, Fluorescência, TAPPI T 452 om-86, Coordenada de cor L*a*b*, TAPPI T 524 om-86, Cinzas na polpa TAPPI T $211 \mathrm{~cm}-86$, Cinzas insolúveis em ácido clorídrico, TAPPI T 244 om-88, Metais (espectrofotometria de absorção atômica), TAPPI T 266 om-88. Concentração de Reagentes: a análise das concentrações iniciais e residuais de cloro, dióxido de cloro, hipocloritos, peróxido de hidrogênio e ditionitos foi efetuada de acordo com KRAFT (1967). A análise das concentrações iniciais e residuais de ozônio foi realizada por Iodometria.

\section{RESULTADOS}

Os resultados do branqueamento das três amostras de polpa pelos vários processos foram interpretados segundo os parâmetros de alvura, rendimentos, fluorescência, coordenada de cor $b^{*}$, viscosidade e número kappa das polpas dos processos de branqueamento.

\section{Alvura}

Verifica-se para Amostra AS, na Figura 1, que o objetivo de alvura de 78-82\% ISO foi atingido pela combinação ozônio-peróxido, mas somente quando foi aplicada uma dosagem elevada de ozônio $(8 \mathrm{~kg} / \mathrm{t}) \mathrm{e}$, ainda, uma etapa adicional de quelação entre os estágios de ozonização e de peroxidação.

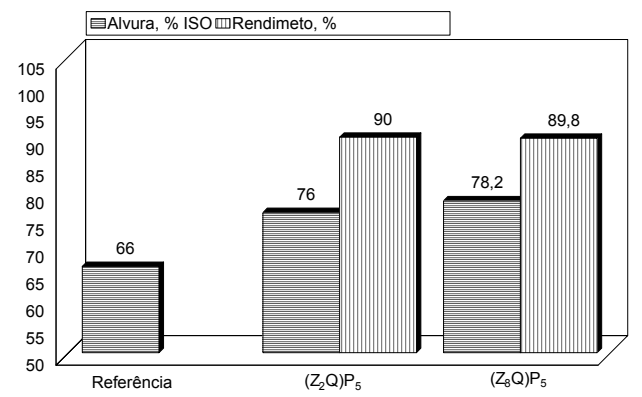

Em que: Estágio de ozônio, $Z$ seguido de uma quelação, Q, (ZQ); e então, estágio de peróxido, P, (ZQ)P. O número em subscrito representa o valor da carga aplicada em $\mathrm{kg}$ do reagente por tonelada de polpa seca.

FIGURA 1: Resultados de alvura e rendimentos da sequência (ZQ)P da Amostra AS.

FIGURE 1: Brightness and yield results of Sample AS bleached by the (ZQ)P sequence.

Embora a alvura-objetivo tenha sido alcançada somente quando se utilizou a dosagem de $8 \mathrm{~kg} / \mathrm{t} \mathrm{de}$ ozônio, na seqüência (ZQ)P, o aumento da dosagem de ozônio por si só teve pouco efeito na alvura da amostra AS (Figura 2). Por exemplo, o aumento da dosagem de ozônio de 2 para $8 \mathrm{~kg} / \mathrm{t}$ resultou em ganho de apenas 2,2 \% ISO de alvura. Entretanto, esse pequeno ganho de alvura, obtido à custa de um excesso de ozônio, tornou possível atingir a alvura-objetivo.

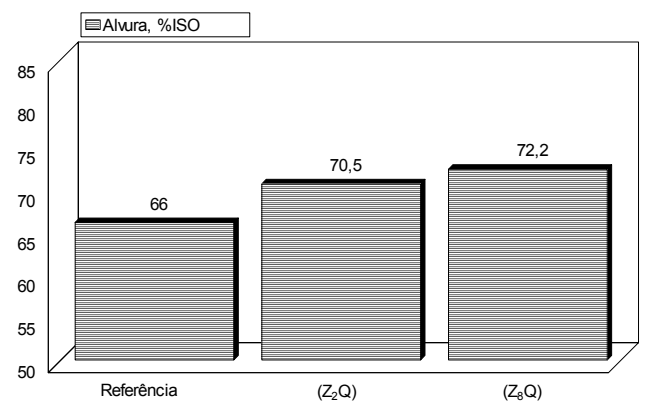

Em que: Estágio de ozônio, $Z$ seguido de uma quelação, Q, (ZQ). O número em subscrito representa o valor da carga aplicada em $\mathrm{kg}$ do reagente por tonelada de polpa seca.

FIGURA 2: Resultados de alvura da sequência (ZQ) da Amostra AS.

FIGURE 2: Brightness of Sample AS bleached by the (ZQ) sequence.

Os resultados da amostra EU apresentados na Figura 3 indicam que a alvura-objetivo de $78-82 \%$ ISO só foi alcançada com a seqüência (ZQ)P, utilizando-se elevada dosagem de peróxido $(25 \mathrm{~kg} / \mathrm{t})$. 


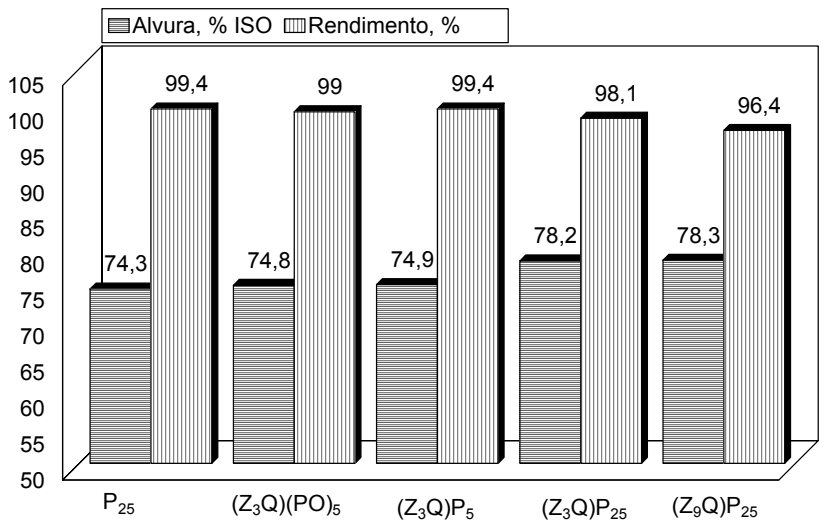

Em que: Estágio de ozônio, $Z$ seguido de uma quelação, Q, (ZQ); e então, estágio de peróxido, $P,(Z Q) P$. Estágio de ozônio, $Z$ seguido de uma quelação, Q, (ZQ); e então, estágio de peróxido pressurizado com oxigênio, (PO), (ZQ)(PO). O número em subscrito representa o valor da carga aplicada em kg do reagente por tonelada de polpa seca.

FIGURA 3: Resultados de alvura e rendimento do branqueamento com um estágio de peroxidação e com as seqüências (ZQ)(PO) e (ZQ)P da Amostra EU.

FIGURE 3: Brightness and yield results of Sample EU bleached by a single peroxide stage by the (ZQ)(PO) and (ZQ)P sequences.

É importante notar que a amostra EU apresentava alvura inicial de 70,4\% ISO, e, considerando ainda que essa amostra possuía elevado número kappa, o processo de branqueamento mais indicado seria, teoricamente, com reagentes que atuam por alvejamento dos grupos cromóforos, como o peróxido de hidrogênio. A aplicação de uma etapa de ozônio, previamente ao branqueamento com peróxido, teve efeito positivo na alvura final da polpa, demonstrando que o ozônio ativa a lignina para o posterior branqueamento com peróxido. No entanto, o ganho de alvura na etapa de ozonização por si só é insignificante, mesmo quando uma elevada dosagem de ozônio foi aplicada ( $9 \mathrm{~kg} / \mathrm{t}$, Figura 4).

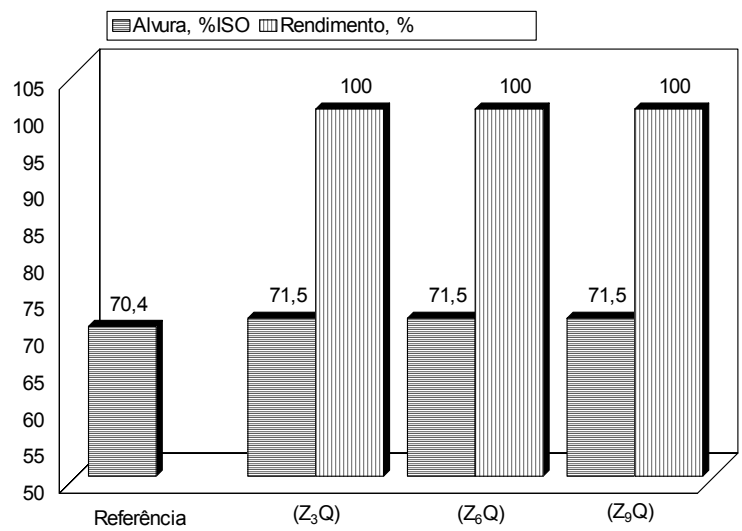

Em que: Estágio de ozônio, $Z$ seguido de uma quelação, Q, (ZQ). O número em subscrito representa o valor da carga aplicada em $\mathrm{kg}$ do reagente por tonelada de polpa seca.

FIGURA 4: Resultados de alvura e rendimento da seqüência (ZQ) da Amostra EU.

FIGURE 4: Brightness of Sample EU bleached by the (ZQ) sequence.

Os estudos prévios de carga de ozônio e peróxido, que devem ser aplicados na sequência (ZQ)P das amostras EU e AS para atingir a alvura objetivo, facilitou determinar as cargas necessárias para atingir o objetivo de alvura com a amostra AN. Essa amostra possuía um maior número kappa e menor alvura que as demais. A sequência que atingiu a alvura de 78-82 ISO foi a $\left(\mathrm{Z}_{10} \mathrm{Q}\right)\left(\mathrm{PO}_{20}\right)$ (Figura 5). 


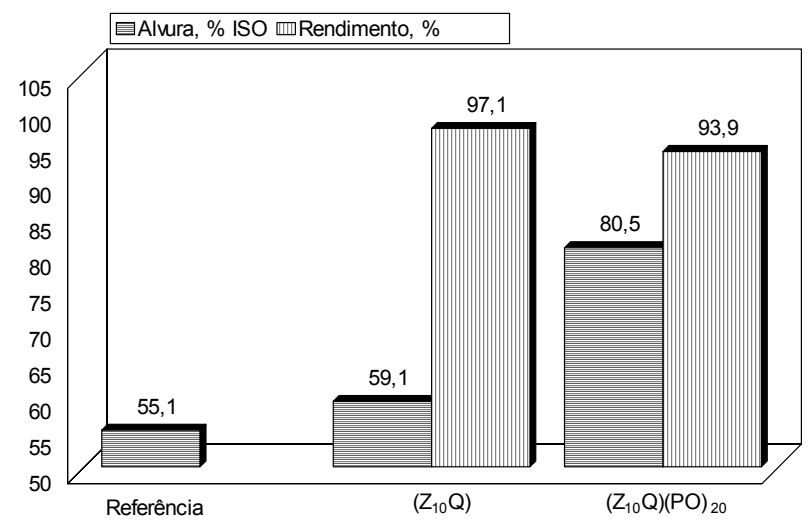

Em que: Estágio de ozônio, $Z$ seguido de uma quelação, Q, (ZQ); e então, estágio de peróxido pressurizado com oxigênio, (PO), (ZQ)(PO). O número em subscrito representa o valor da carga aplicada em $\mathrm{kg}$ do reagente por tonelada de polpa seca.

FIGURA 5: Resultados de alvura e rendimento do branqueamento pelos processos (ZQ) e (ZQ)(PO), Amostra AN.

FIGURE 5: Brightness and yield results of Sample AN bleached by the (ZQ) and (ZQ)(PO) sequences.

\section{Rendimento}

Os rendimentos dos processos de branqueamento avaliados para a amostra AS estão apresentados na Figura 1. O rendimento dos vários processos ficou na faixa de $90 \%$, indicando uma perda de material durante o branqueamento da ordem de $10,0 \%$. Esse rendimento pode ser considerado baixo para a operação de branqueamento e pode ser atribuído ao elevado teor de cinzas presente na polpa, as quais são eliminadas quase que totalmente durante o branqueamento. Os processos, que causaram maior perda de rendimento foram aqueles que envolveram uma etapa fortemente alcalina de deslignificação com oxigênio. Os processos envolvendo ozônio e peróxido apresentaram rendimentos similares entre si. Enquanto que a redução do número kappa foi de apenas 3,9 unidades e de viscosidade de 3,6 cP não sendo, portanto, responsáveis pelos baixos rendimentos.

O rendimento do branqueamento da amostra EU foi bastante elevado, acima de $98 \%$, indicando perdas insignificantes no processo de branqueamento. A maior perda de rendimento foi observada para o processo (ZQ)P, com uma aplicação de $25 \mathrm{~kg}$ de peróxido de hidrogênio por tonelada de polpa (Figura 3). A redução do número kappa foi de apenas 5,2 unidades e de viscosidade $1,1 \mathrm{cP}$ resultados que explicam os altos rendimentos dos processos de branqueamentos.

O rendimento do branqueamento da amostra AN foi de 94\% (Figura 5). Este rendimento é similar a de uma polpa de fibra virgem, utilizando uma seqüência com deslignificação com oxigênio, atingindo uma redução do número kappa, 9,4 unidades, mas a redução da viscosidade foi bem inferior, 3,4 cP, para o processo de branqueamento com fibras secundárias.

\section{Fluorescência}

O valor de 10,17\% ISO de fluorescência determinado, originalmente, na amostra AS pode ser considerado alto para uma polpa que apresentava número kappa de apenas 7,3. Para muitas aplicações de fibras secundárias, a presença de fluorescência na polpa pode ser irrelevante, mas, para fabricação de papéis que têm contato com a pele, como "tissue", ou com alimentos, como embalagens para líquidos, a presença de fluorescência é indesejável. O aumento da fluorescência causado por estágios individuais de peroxidação pode ser explicado pela ação do peróxido na transformação de grupos cromóforos, como aldeídos e cetonas, em grupos auxocromos, como ácidos carboxílicos, os quais deslocam o máximo de absorção de luz da região do visível para a região do ultravioleta $(400-700 \mathrm{~nm})$.

Resultados significativos de remoção de fluorescência foram obtidos no tratamento da polpa com ozônio (Z), e mais significativos ainda quando o ozônio foi seguido do branqueamento com peróxido (ZQ)P, (Figura 6). Na Figura 7, é mostrado o efeito da dosagem de ozônio na remoção de fluorescência. Os resultados indicam uma remoção substancial de fluorescência com a dosagem de $2 \mathrm{~kg} / \mathrm{t}$ de ozônio. 
Entretanto, acima dessa dosagem, o efeito do ozônio na fluorescência é menos pronunciado.

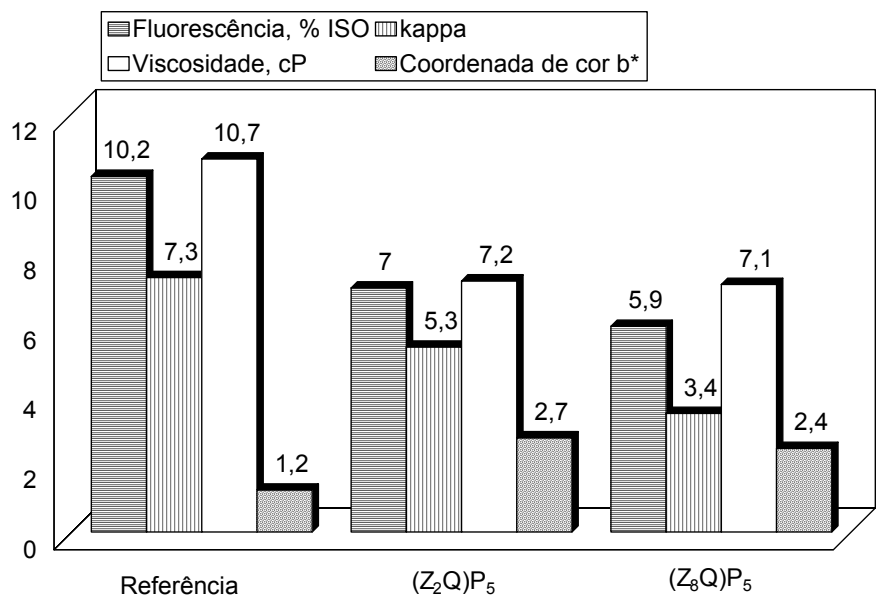

Em que: Estágio de ozônio, $Z$ seguido de uma quelação, Q, (ZQ); e então, estágio de peróxido, $P,(Z Q) P$. O número em subscrito representa o valor da carga aplicada em $\mathrm{kg}$ do reagente por tonelada de polpa seca.

FIGURA 6: Resultados de fluorescência, kappa, viscosidade e coordenada de cor b* da sequência (ZQ)P da Amostra AS.

FIGURE 6: Fluorescence, kappa, viscosity and $b^{*}$ color coordinate results of Sample AS bleached by the (ZQ)P sequence.

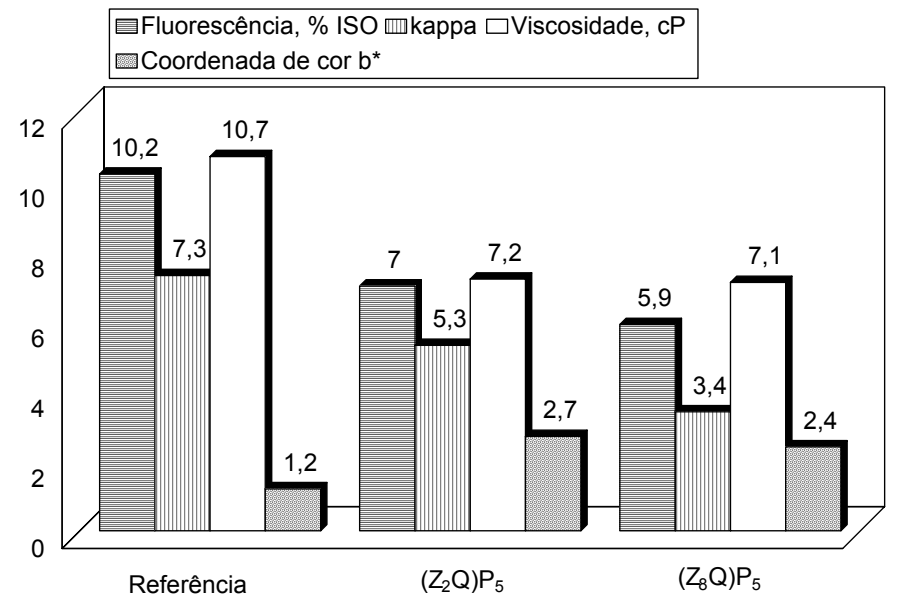

Em que: Estágio de ozônio, $Z$ seguido de uma quelação, Q, (ZQ); e então, estágio de peróxido, $\mathrm{P},(\mathrm{ZQ}) \mathrm{P}$. O número em subscrito representa o valor da carga aplicada em $\mathrm{kg}$ do reagente por tonelada de polpa seca.

FIGURA 7: Resultados de fluorescência, kappa, viscosidade e coordenada de cor b* da sequência (ZQ) da Amostra AS.

FIGURE 7: Fluorescence, kappa, viscosity and $b^{*}$ color coordinate results of Sample AS bleached by the (ZQ) sequence.

O ozônio remove fluorescência pela destruição de ligações duplas, especialmente conjugadas, existentes em corantes, as quais são fortes absorvedoras de luz ultravioleta. Quando o peróxido é aplicado após o ozônio, verifica-se alguma redução de fluorescência, que ocorre, possivelmente, pela extração alcalina de pigmentos fluorescentes existentes na polpa que foram previamente atacados e modificados pelo ozônio.

O tratamento das amostras (EU) e (AN) com ozônio reduziu substancialmente a fluorescência da polpa (Figuras 8 e 10). Contudo, as etapas de peróxido $(25 \mathrm{~kg} / \mathrm{t})$, que seguiram à ozonização, aumentaram novamente a fluorescência da polpa, enquanto que com aplicação de apenas $5 \mathrm{~kg} / \mathrm{t}$ nas etapas de peroxidação ocorreu a remoção da fluorescência (Figuras 9 e 10). 


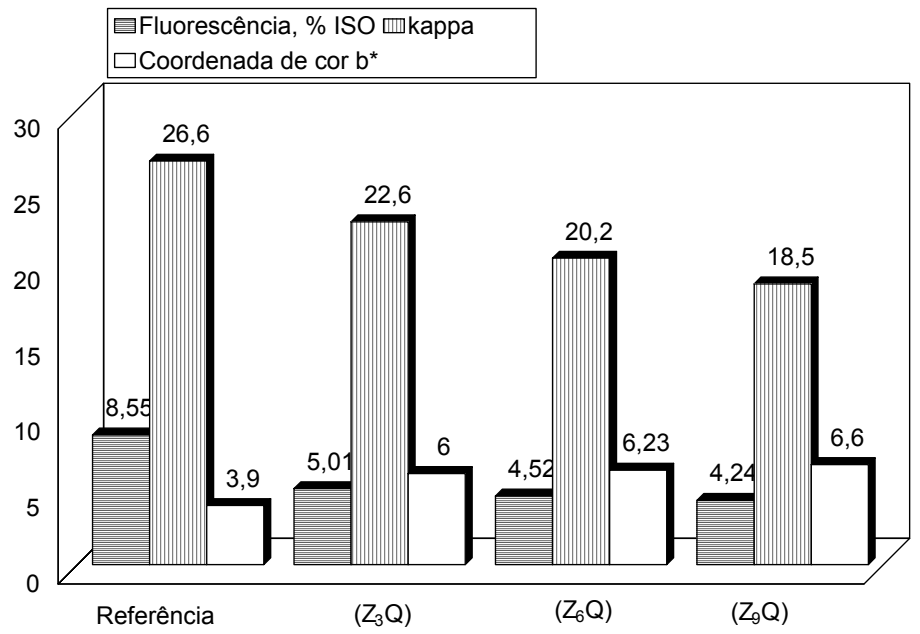

Em que: Estágio de ozônio, $Z$ seguido de uma quelação, Q, (ZQ). O número em subscrito representa o valor da carga aplicada em $\mathrm{kg}$ do reagente por tonelada de polpa seca.

FIGURA 8: Resultados de fluorescência, kappa, e coordenada de cor b* da sequência (ZQ) da Amostra EU.

FIGURE 8: Fluorescence, kappa, viscosity and $b^{*}$ color coordinate results of Sample EU bleached by the (ZQ) sequence.

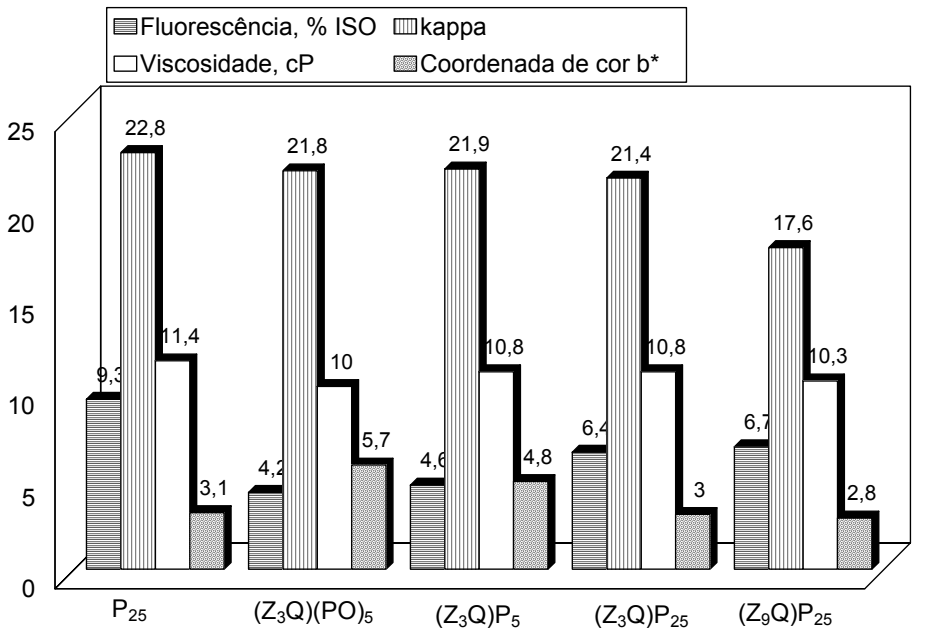

Em que: Estágio de ozônio, $Z$ seguido de uma quelação, Q, (ZQ); e então, estágio de peróxido, $P,(Z Q) P$. Estágio de ozônio, $Z$ seguido de uma quelação, $Q$, (ZQ); e então, estágio de peróxido pressurizado com oxigênio, $(\mathrm{PO}),(\mathrm{ZQ})(\mathrm{PO})$. $\mathrm{O}$ número em subscrito representa o valor da carga aplicada em $\mathrm{kg}$ do reagente por tonelada de polpa seca.

FIGURA 9: Resultados de fluorescência, kappa, viscosidade e coordenada de cor $b^{*}$ do branqueamento com um estágio de peroxidação e com as seqüências (ZQ)(PO) e (ZQ)P da Amostra EU.

FIGURE 9: Fluorescence, kappa, viscosity and $b^{*}$ color coordinate results of Sample EU bleached by the $(\mathrm{ZQ})(\mathrm{PO})$ and $(\mathrm{ZQ}) \mathrm{P}$ sequences.

\section{Coordenada de cor $b^{*}$}

A coordenada de cor b* indica o grau de pigmentação amarela existente na polpa. Os efeitos dos vários processos de branqueamento na coordenada de cor $b^{*}$ estão apresentados na Figura 6. Verifica-se que todos os processos de branqueamento resultaram em aumento dos valores da coordenada de cor $\mathrm{b}^{*}$ da amostra AS, a qual tinha um valor original de 1,2. O branqueamento com ozônio $(Z)$ aumentou a coordenada de cor $b^{*}$ da polpa apenas ligeiramente, (Figura 7). Esse aumento pode ser em conseqüência da ação do ozônio na estrutura do corante, que passou a refletir maiores quantidades de luz na região do amarelo. Quando a ozonização foi seguida de estágio alcalino, em processo como (ZQ)P, os valores da coordenada de cor $b^{*}$ aumentaram substancialmente. Na Figura 6, quando se comparam os processos $\left(Z_{2} Q\right) P$ e $\left(Z_{8} Q\right) P$, 
verifica-se que o aumento da dosagem de ozônio de 2 para $8 \mathrm{~kg} / \mathrm{t}$ de polpa teve influência irrisória na coordenada de cor $\mathrm{b}^{*}$.

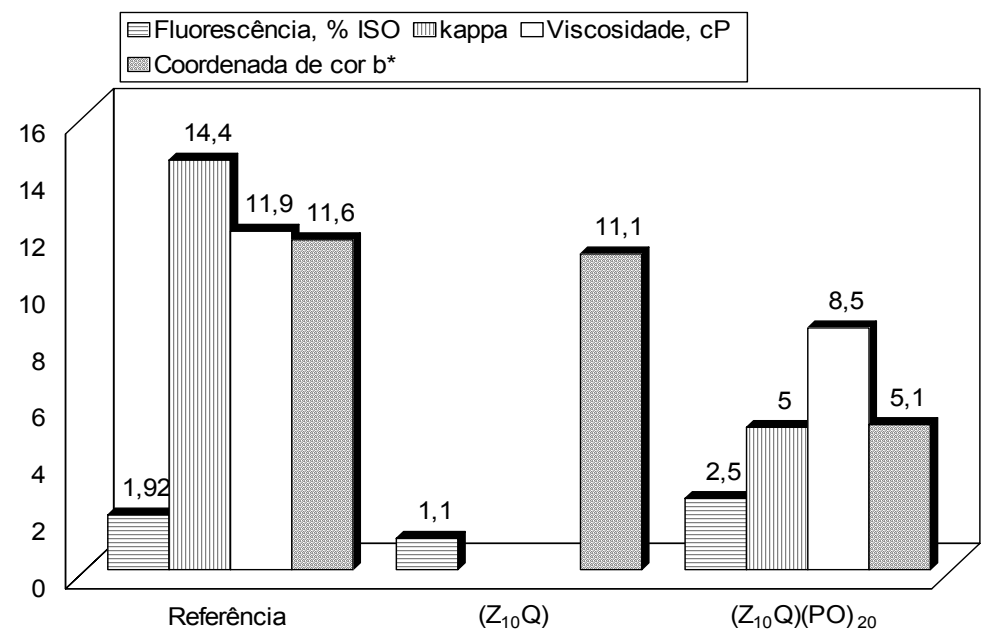

Em que: Estágio de ozônio, Z seguido de uma quelação, Q, (ZQ); e então, estágio de peróxido pressurizado com oxigênio, (PO), (ZQ)(PO). O número em subscrito representa o valor da carga aplicada em $\mathrm{kg}$ do reagente por tonelada de polpa seca.

FIGURA 10: Resultados de fluorescência, kappa, viscosidade e coordenada de cor $b^{*}$ da seqüência $(\mathrm{ZQ})(\mathrm{PO})$ e (ZQ) da Amostra AN.

FIGURE 10: Fluorescence, kappa, viscosity and $b^{*}$ color coordinate results of Sample AN bleached by the $(\mathrm{ZQ})(\mathrm{PO})$ and $(\mathrm{ZQ})$ sequences.

A Figura 8 apresenta resultados da polpa EU, mostrando que o ozônio tendeu a aumentar os valores da coordenada de cor $b^{*}$ o que pode também ser explicado pela ação eletrofílica do ozônio em certos grupos cromóforos da lignina. No caso da amostra em questão que apresentava alto número kappa, a redução da coordenada de cor $b^{*}$ depende, especificamente, de reagentes alvejantes que atuam nucleofilicamente na lignina.

A Figura 10 apresenta resultados da polpa AN que teve uma redução superior a $50 \%$ na coordenada de cor $b^{*}$, que pode ser explicado pela reação nucleofílica do peróxido com os grupos cromóforos presentes na polpa.

\section{Número kappa e viscosidade da polpa}

Na Figura 6, são apresentados os valores de kappa e viscosidade resultante do tratamento da amostra AS pelos vários processos de branqueamento. Muito provavelmente, grande parte do número kappa de 7,3 da amostra AS é proveniente de componentes da polpa que não são propriamente ligninas e, sim, outros aditivos utilizados na fabricação dos papéis que derivaram as fibras secundárias. O branqueamento com peróxido teve efeito substancialmente negativo na viscosidade, enquanto reduziu o número kappa da polpa apenas ligeiramente; essa tendência pode ser verificada nas Figuras 6 e 7. Resultados mais substanciais de redução do número kappa foram obtidos com o processo envolvendo ozônio, (ZQ). O branqueamento com o processo envolvendo ozônio teve pouco efeito na viscosidade da polpa, a Figura 7 ilustra essa tendência, que é de certa forma surpreendente, considerando-se o alto poder oxidante do ozônio. A alta seletividade do ozônio pode, talvez, ser explicada pelo baixo teor de lignina presente na amostra AS. Altos teores de lignina na polpa podem reduzir, significativamente, a seletividade do branqueamento com ozônio (Colodette et al., 1996).

O tratamento com ozônio, Figura 8, apresenta os resultados de número kappa da polpa EU o qual foi ligeiramente decrescido quando se aumentou a carga de ozônio no processo de branqueamento, mas não significativamente. Em todos os casos, foi observado um número kappa residual de 18-22 na polpa branqueada. Por outro lado, a viscosidade da polpa também não foi substancialmente afetada nos vários processos de branqueamento (Figura 9). 
A Figura 10 mostra os resultados da polpa AN a qual apresenta um alto número kappa residual (5) que poderá influenciar no aumento da reversão de alvura, e em uma viscosidade final baixa $(8,5)$, podendo resultar em quebras na formação da folha de papel.

\section{CONCLUSÕES}

Neste estudo, foram avaliadas seqüencias TCF para o branqueamento de celulose de fibras secundárias destintadas provenientes de diferentes origens (AS, AN e EU). As polpas foram branqueadas a um nível mínimo de alvura de $78 \%$ ISO, sendo que o requerimento de reagentes e as principais propriedades das polpas foram avaliadas. Os resultados desse estudo levaram às seguintes conclusões principais:

As seqüências mais adequadas para o branqueamento por processos TCF são (ZQ)P e (ZQ)(PO) independente da origem da polpa.

O rendimento do processo de branqueamento depende da origem da polpa de fibra secundária. requeridas.

A presença do ozônio é fundamental no branqueamento TCF, especialmente quando altas alvuras são

O ozônio é um reagente efetivo na remoção de fluorescência de celulose de fibras secundárias, enquanto que o peróxido de hidrogênio aumenta a fluorescência da polpa. secundárias.

O peróxido de hidrogênio é muito efetivo para remover a coordenadas de cor $b^{*}$ de fibras

Uma etapa de remoção de metais Q é absolutamente necessária para o branqueamento de celulose de fibras secundárias por processos TCF.

As viscosidades finais das polpas de fibras secundárias foram baixas, enquanto que os números kappa foram altos.

\section{REFERÊNCIAS BIBLIOGRÁFICAS}

CANADIAN PULP AND PAPER ASSOCIATION (CPPA). Technical section standard test methods. Montreal, 1986.

COLODETTE, J.L. et al. Factors affecting kraft pulp bleachability with oxygen derived chemicals. In: NONCHLORINE BLEACHING CONFERENCE, 1996, Orlando. Anais... Orlando: s.n., 1996. 20p.

D’ALMEIDA, M.L.; CAHEN, R. Reciclagem de papel. O Papel, São Paulo, v.52, n.11, p. 131-135, 1991.

DALTON, A. I. AIR PRODUCTS AND CHEMICALS. Aperfeiçoamento na deslignificação de fibra contendo lignocelulose. Int. CI ${ }^{4}$ D21C 9/14. BRn. PI 9004674 A. 19 set. 1990; 10 set. 1991.

Kraft, P. In: MCDONALD, R.G. (Ed.). Pulp \& paper manufacture. 2nd ed. New York : McGraw-Hill Book Company, 1967. p. 628-725

NADDEO, R.C; DALTON, A.I. AIR PRODUCTS AND CHEMICALS. Processo de descoramento e alvejamento de polpa compreendendo fibra celulósica secundária. Int. $\mathrm{CI}^{4}$ D21C 9/14. BRn. PI 9004623 A. 17 set. 1990; 10 set. 1991.

NADDEO, R.C.; HRISTOFAS, K. ; MAGNOTTA, V.L. AIR PRODUCTS AND CHEMICALS. Oxygen color stripping in secondary fibers recovery. Int. CI ${ }^{5}$ D21C 5/02. BRn. PI 9201920 A. 21 maio 1992; 5 jan. 1993a.

NADDEO, R.C.; HRISTOFAS, K. ; MAGNOTTA, V.L. AIR PRODUCTS AND CHEMICALS. Dye removal in oxygen color stripping of secondary fibers. Int. $\mathrm{CI}^{5}$ D21C 5/02. USn.5,211,809. 21 May 1991; 18 May 1993b.

NADDEO, R.C.; HRISTOFAS, K. ; MAGNOTTA, V.L. AIR PRODUCTS AND CHEMICALS. Dye stripping by oxygen and peroxide in secondary fiber recovery. Int. CI ${ }^{5}$ D21C 5/02. USn. 5,324,390. 2 Mar. 1993; 28 June 1994a.

NADDEO, R.C.; HRISTOFAS, K. ; MAGNOTTA, V.L. AIR PRODUCTS AND CHEMICALS. Dye stripping by oxygen in secondary fiber recovery. Int. CI ${ }^{5}$ D21C 5/02. USn. 5,324,390. 3 Mar. 1993; 26 Jul. 1994b.

NADDEO, R.C. et al. Oxidative methods offer alternative to chlorine bleaching of wasterpper. Pulp and Paper, Atlanta, v.66, n.11, p. 71-81,1992.

PATT, R. et al. New approaches in bleaching of recycled fibers. Tappi Journal, Atlanta, v.79, n.12, p. 143-151, 1996. 
SINGH, R.P. Bleaching. In: HENMILTON, F., LEOPODO, B. (Eds.). Pulp and paper manufacture. 3.ed. Atlanta: Tappi, 1987. v.3, p.234 - 237.

STUS, W.L. Color stripping of recycled wood-free papers using ozone. Kalamazoo, Michigan: Western Michigan University, 1996. 59p. (A Thesis to requirements for the Senior Design PAPR 473 Course).

TECHNICAL ASSOCIATION OF THE PULP AND PAPER INDUSTRY (TAPPI). Test methods. Atlanta, 1998-1999. paginação irregular. 